\title{
Ultrasound screening for asymptomatic carotid stenosis in subjects with calcifications in the area of the carotid arteries on panoramic radiographs: a cross-sectional study
}

\author{
Elias P Johansson ${ }^{1 *}$, Jan Ahlqvist ${ }^{2}$, Maria Garoff' ${ }^{2}$ Kjell Karp ${ }^{3}$, Eva Levring Jäghagen ${ }^{2}$ and Per Wester ${ }^{1}$
}

\begin{abstract}
Background: Directed ultrasonic screening for carotid stenosis is cost-effective in populations with > 5\% prevalence of the diagnosis. Occasionally, calcifications in the area of the carotid arteries are incidentally detected on odontological panoramic radiographs. We aimed to determine if directed screening for carotid stenosis with ultrasound is indicated in individuals with such calcifications.

Methods: This was a cross-sectional study. Carotid ultrasound examinations were performed on consecutive persons, with findings of calcifications in the area of the carotid arteries on panoramic radiography that were otherwise eligible for asymptomatic carotid endarterectomy.

Results: Calcification in the area of the carotid arteries was seen in 176 of 1182 persons undergoing panoramic radiography. Of these, 117 fulfilled the inclusion criterion and were examined with carotid ultrasound. Eight persons (6.8\%; 95\% Cl 2.2-11.5\%) had a carotid stenosis - not significant over the 5\% pre-specified threshold $(\mathrm{p}=$ 0.232 , Binomial test). However, there was a significant sex difference $(p=0.008)$, as all stenoses were found in men. Among men, $12.5 \%(95 \% \mathrm{Cl} 4.2-20.8 \%)$ had carotid stenosis - significantly over the $5 \%$ pre-specified threshold $(p=$ 0.014, Binomial test).

Conclusions: The incidental finding of calcification in the area of the carotid arteries on panoramic radiographs should be followed up with carotid screening in men that are otherwise eligible for asymptomatic carotid endarterectomy.

Trial Registration: The study was registered at http://www.clinicaltrials.gov; NCT00514644
\end{abstract}

\section{Background}

In patients with asymptomatic carotid stenosis, carotid endarterectomy (CEA) reduces the net risk of stroke and perioperative events at $5[1]$ and 10 years follow-up [2]. Patients $\geq 75$ years of age do not benefit from asymptomatic CEA [2]. The benefit of asymptomatic CEA has come into question since a lower risk of stroke without CEA has been shown in recent observational studies compared to the randomized studies [3]. This can, at least in part, be explained by that lipid lowering

\footnotetext{
* Correspondence: elias.johansson@medicin.umu.se

'Department of Public Health and Clinical Medicine, Umeå University, Umeå, Sweden

Full list of author information is available at the end of the article
}

medications were less commonly used during the time period of these randomized trials [3]. Current guidelines suggest that asymptomatic CEA should only be performed when the perioperative risk is low [4-6]. One ongoing randomized study will determine if patients with statin and other cardiovascular preventive treatment benefit from asymptomatic CEA [7]. There is limited but promising evidence that improved patient selection to asymptomatic CEA can be achieved by plaque characteristics, microemboli detection and cerebrovascular reactivity testing [8-10].

In a systematic review, the prevalence of asymptomatic carotid stenosis was $7.5 \%$ in men aged $\geq 80$ years, $5.0 \%$ in women aged $\geq 80$ years, $2.3 \%$ in men aged $60-69$ years
C Biomed Central

(ㄷ) 2011 Johansson et al; licensee BioMed Central Ltd. This is an Open Access article distributed under the terms of the Creative Commons Attribution License (http://creativecommons.org/licenses/by/2.0), which permits unrestricted use, distribution, and reproduction in any medium, provided the original work is properly cited. 
and $2.0 \%$ in women aged 60-69 years [11]. Asymptomatic carotid stenosis can be detected incidentally - e.g. detection of a contralateral lesion when examining patients after a transient ischemic attack (TIA) or stroke - or by directed screening. Directed screening for asymptomatic carotid stenosis is suggested to be cost-effective in populations with $>5 \%$ prevalence and low perioperative risk, and in populations with $>20 \%$ prevalence of carotid stenosis and moderate perioperative risk [12].

In practice, panoramic radiographs are performed prior to routine dental care, implant placement, trauma, and local cancer treatment. In $3.5-4.2 \%$ of these persons, a calcification in the area of the carotid artery is detected [13,14] (see Figure 1). A calcification in the area of the carotid arteries might indicate a carotid stenosis, since the calcification could be part of an atherosclerotic plaque that reduces the lumen more than $50 \%$. Some carotid stenoses contain calcifications while others do not. In two previous studies, 85 individuals with calcifications in the area of the carotid artery were examined with carotid ultrasound; $50-99 \%$ carotid stenosis was detected in $26 \%$ of the corresponding carotid arteries [13,14].

The aim of this study is to determine if screening with carotid ultrasound is indicated in persons, otherwise eligible for asymptomatic CEA, with calcification in the area of the carotid arteries incidentally detected on panoramic examinations. Screening is considered indicated if the prevalence of stenosis exceeds $5 \%$.

\section{Methods}

\section{Study group}

We interpreted 1182 consecutive panoramic examinations for calcifications in the area of the carotid arteries in a prospective manner. Persons $<18$ or $\geq 75$ years are not eligible for asymptomatic CEA and were not included [1,2]. Examinations were performed at the department of Oral and Maxillofacial Radiology, Umeå,
Sweden, between August $1^{\text {st }} 2007$ and February $26^{\text {th }}$ 2009. Age, sex, and indication for the examination were recorded for all persons.

When calcification in the area of the carotid arteries was detected on a panoramic radiograph the radiographic examination was extended with an anterio-posterior projection (APP) of the neck. If the APP confirmed the calcification the individual was included in the study if they were otherwise eligible for asymptomatic CEA. We excluded persons with cancer or other serious co-morbidities whom were not eligible for asymptomatic CEA due to a short life expectancy and/ or increased perioperative risk. We excluded all persons with a previous stroke or TIA since we aimed to study persons without any pervious cerebrovascular event. Refer to Figure 1 and 2 for an example of a calcification in the carotid arteries detected on a panoramic radiograph and confirmed on an APP. Medical records were reviewed of all participants, see Figure 3 for trial profile.

\section{Reference group}

We selected a sex- and age-matched reference group in order to determine if persons with calcification in the area of the carotid arteries have an average or above average burden of atherosclerotic disease. The reference participants were recruited among the persons in whom the panoramic examination did not reveal any calcification in the area of the carotid arteries (Figure 3). One hundred ninety-eight reference persons were randomly selected. Their medical background was assessed via questionnaire; 79 were excluded based on questionnaire results (Figure 4). The reference population did not undergo carotid ultrasound.

\section{Subgroups}

Pre-specified subgroups were based on sex, age, and the cause of referral for the panoramic radiograph examination. With all persons $\geq 75$ years excluded, we chose

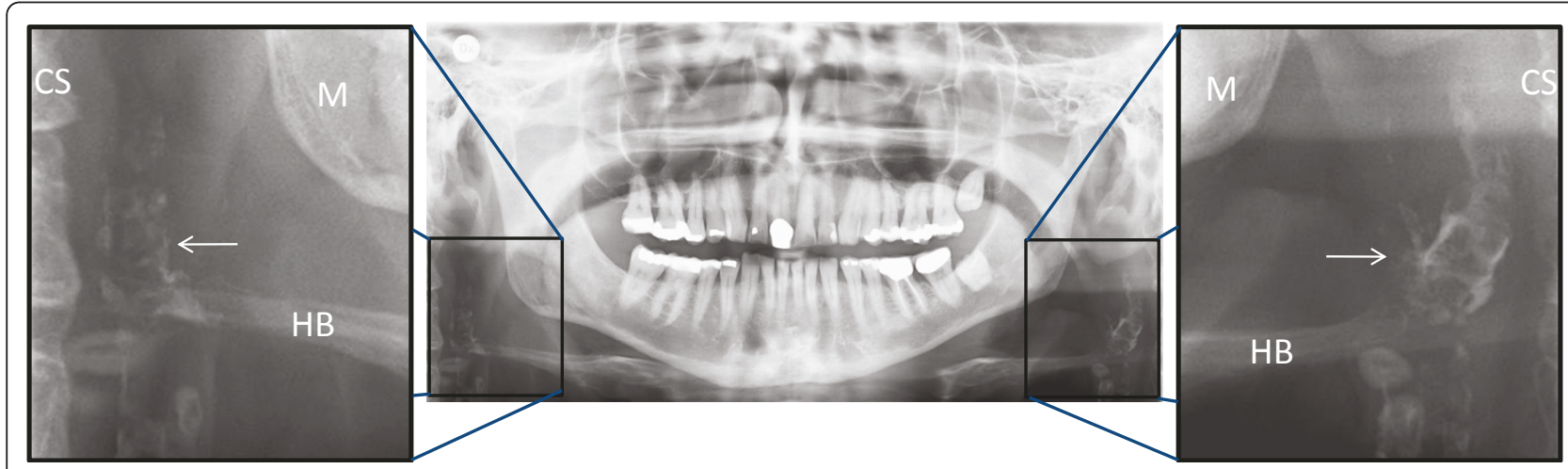

Figure 1 Panoramic image. Showing bilateral calcification in the area of the carotid arteries (arrows). (M = mandible, $C S=c e r v i c a l ~ s p i n e, ~ H B=$ hyoid bone). 


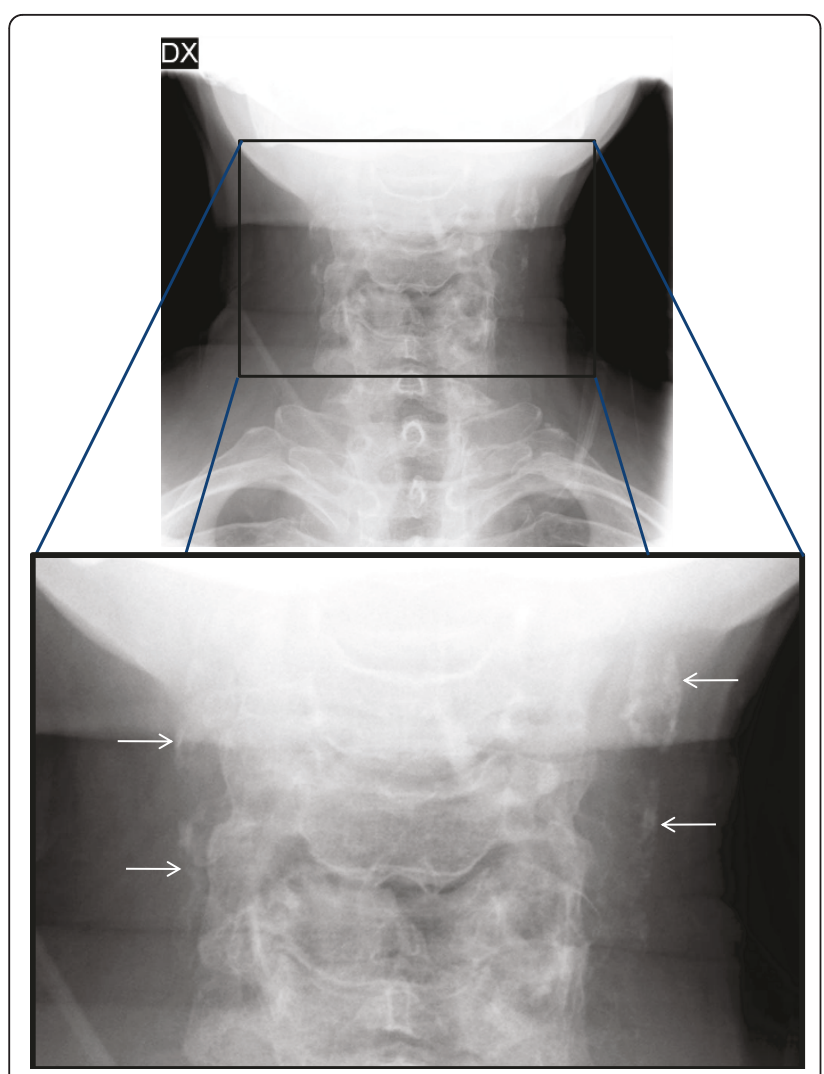

Figure 2 Anterio-posterior projection of the neck. Showing calcifications in the area of the carotid arteries (arrows) adjacent to the cervical spine.

subgroups based on age of $<65$ years and $65-74$ years since these were the age groups used in ACST-study $[1,2]$. The cause of referral was divided into three subgroups:

1. Regular dental: Examinations performed in all practices using panoramic radiographs, e.g. dental and implant treatment.

2. Specialised dental: Examinations performed in specialist dental clinics such as fractures and orthodontics.

3. Specialised medical: Examinations routinely performed prior to medical intervention, such as heart valve surgery.

Since there were a low number of included persons in the subgroups "specialised dental" and "specialised medical", these two subgroups were merged for analyses.

Pre-specified cardiovascular subgroups were cardiovascular event as a combined group and for each parameter separately as follows: prior myocardial infarction, current angina pectoris, heart failure, symptomatic peripheral artery disease, or other relevant cardiovascular event. Cardiovascular risk factor was used as a combined group and for each parameter separately as follows: diabetes, hypertension, current smoking, or current usage of antihypertensive medication, lipid lowering medication, or platelet inhibiting or anticoagulant medication.

\section{Procedures}

Panoramic examinations were performed with an Orthopantomograph ${ }^{\circledR}$ OP100, Finland, using the P1-program. APP examinations were performed using a Cranex ${ }^{\circledR}$ Cephalostat, Soredex, Finland, exposed with $81 \mathrm{kV}$ and $10 \mathrm{~mA}$, for 0.8-1.2 $\mathrm{s}$ depending on patient size. The APP gives an almost orthogonal projection of the region relative to the panoramic projection and increases the possibility to make a correct interpretation of the position of the calcification [14]. The images were captured with the image plate system, Fujifilm FCR. Fuji IP cassette type cc, size $15 \times 30$ (panoramic examination) and $18 \times 24 \mathrm{~cm}$ (APP), respectively, Fuji Photofilm Co., LTD, Japan, were used and an image reader, Fujifilm FCR Capsula XL, Japan, was used for scanning. All images were interpreted using the $C R^{\circledR}$ DICOM 3.5 software, Schick, USA in a room allowing ultimate dim light conditions. The screens used were RadiForce R22 diagnostic computer screen from Eizo Nanao Corporation, Japan, or the 19-inch diagnostic LCD monitor from Olórin, Sweden.

Two experienced specialists in oral and maxillofacial radiology (JA, ELJ) separately re-evaluated the panoramic examination and APP of the included persons with calcification in the area of the carotid arteries. The interreader kappa was 0.69 . For study inclusion/exclusion a consensus decision was reached for all neck sides.

Carotid ultrasound examinations were performed by experienced vascular sonographers blinded to the results of the panoramic examination. A Siemens Acuson Sequoia $512^{\circledR}$ ultrasound system with an 8L5 linear transducer was in all examinations. A visible plaque detected in B-mode with a maximum systolic velocity in the internal carotid artery of $1.45-2.4 \mathrm{~m} / \mathrm{s}$ and $>2.4 \mathrm{~m} / \mathrm{s}$ was considered as $50-69 \%$ and as $70-99 \%$ carotid stenosis, respectively. Carotid occlusion was diagnosed if there was no detectable flow [15]. These criteria have previously been validated locally [16].

\section{Statistics}

We calculated prevalence with $95 \%$ confidence intervals. To determine if the prevalence of carotid stenosis was significant above $5 \%$ we used the one-tailed nonparametric binomial test with the exact calculation method; we chose this test for significance over the lower boundary of the 95\% confidence interval since the latter has lower statistical power and is only an approximation for binary variables (whereas the binomial test is an exact measurement for binary variables). Significance of differences between various groups was determined with the chi-2-test or 


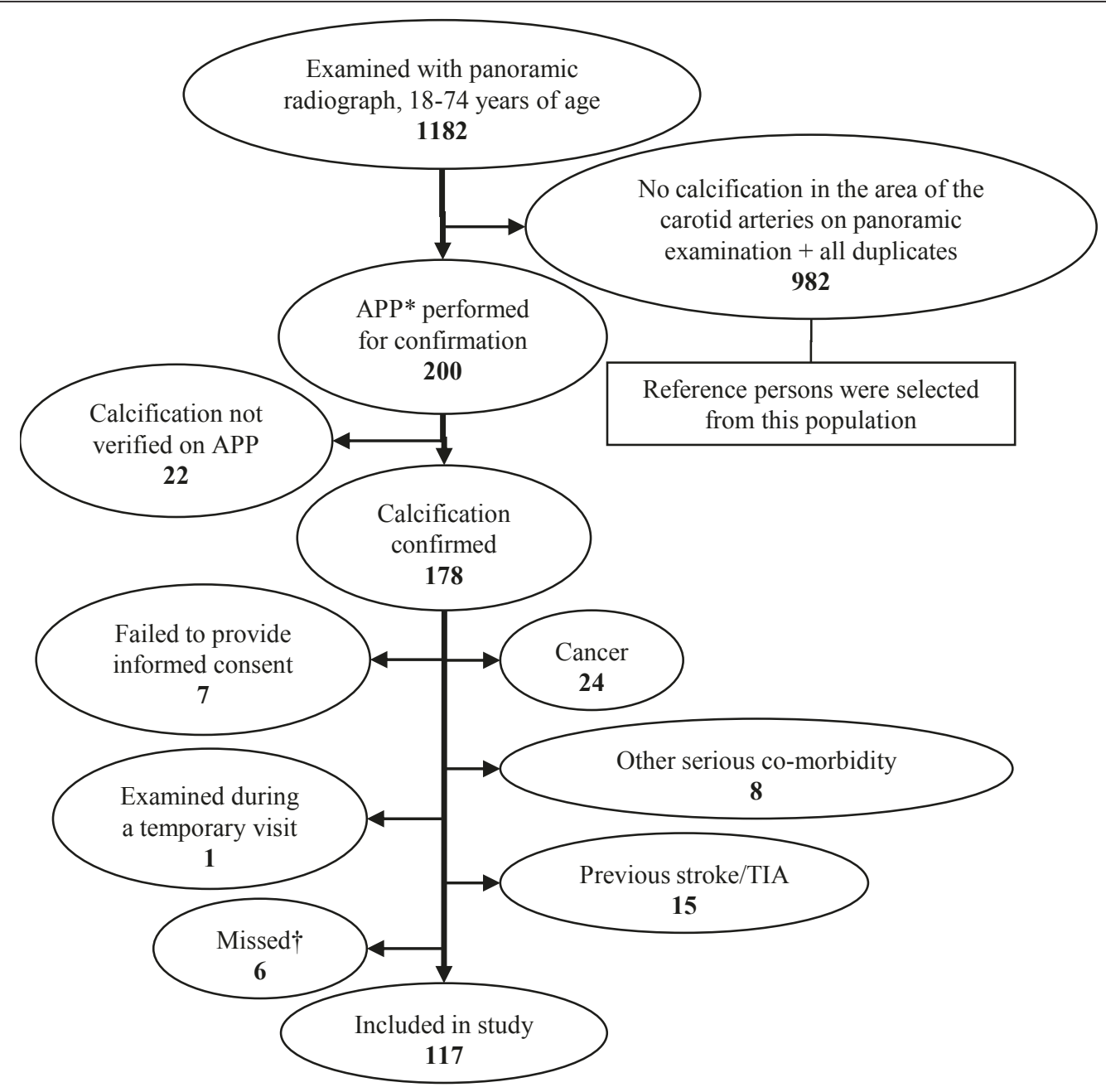

*Anterio-posterior projection.

$\uparrow$ Some of the examinations with a finding of a calcification in the area of the carotid arteries were not interpreted by JA or ELJ the same day as the examination, in most these cases the person was reached for the purpose of this study; these six missed persons were for various reasons not reached.

Figure 3 Trial profile.

t-test; in all analyses of the prevalence of carotid stenosis, the presented subgroups were pre-specified. We preselected a p-value $<0.05$ as cut-off for all relevant calculations. SPSS version 17.0 was used for all calculations.

The sample size was determined by an interim analysis after inclusion of 100 persons that had undergone carotid ultrasound examination. After the interim analysis the study inclusion was closed. The sample size of reference persons was aimed to include at least as many reference participants as there were non-reference participants.

\section{Ethical considerations}

The Regional Ethical Review Board in Umeå approved this study. The study was registered at http://www. clinicaltrials.gov, NCT00514644 before it was launched. All included and reference persons provided informed consent.

\section{Results}

Calcification in the area of the carotid arteries, seen in panoramic radiographs and confirmed with an APP, was detected in 178 persons. We excluded 61 persons with calcification in the area of the carotid arteries since they either were not eligible for asymptomatic CEA, had a history of stroke or TIA, or were not able to participate in the study (Figure 3). See Table 1 for baseline characteristics.

Eight of the included persons with a calcification in the area of the carotid arteries $(6.8 \%, 8 / 117 ; 95 \%$ CI 2.2 - 


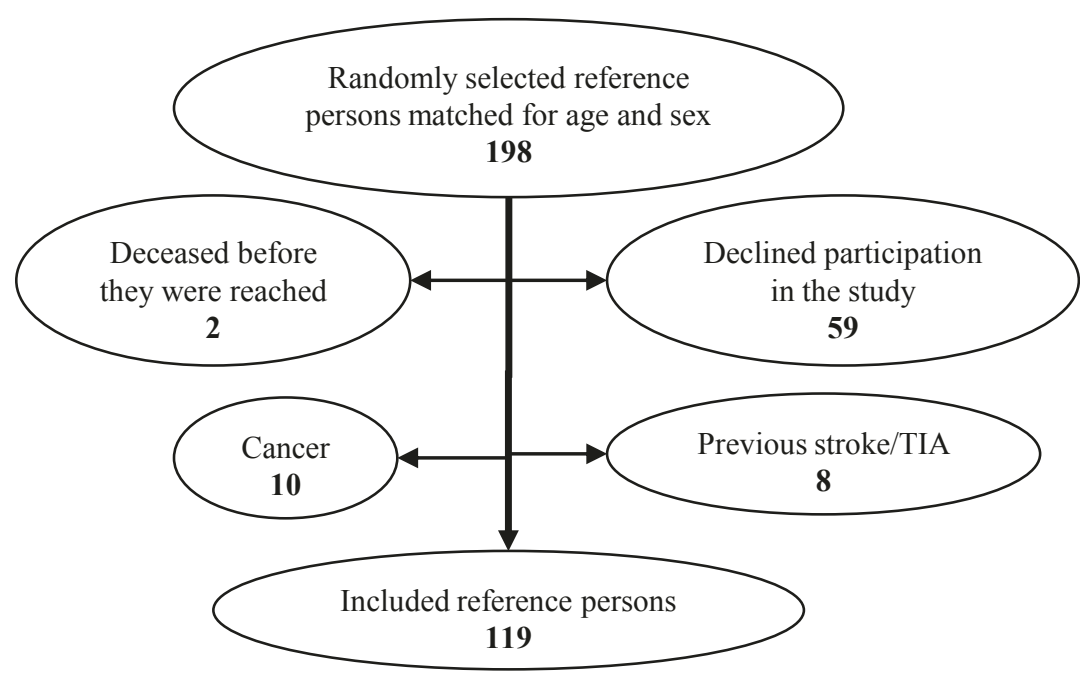

Figure 4 Reasons for reference persons to be excluded from the study.

$11.5 \%)$ had in total nine vessels with $50-99 \%$ stenosis not significantly over the $5 \%$ pre-specified threshold, $\mathrm{p}=$ 0.232 (binomial test).

We detected subgroup differences in the prevalence of $50-99 \%$ carotid stenosis (Table 2). The prevalence was significantly higher among men (12.5\%; 95\% CI 4.2$20.8 \%)$, persons with previous myocardial infarction (16.7\%; 95\% CI 0.6-32.7\%), current angina (23.5\%; 95\% CI 1.1-46.0\%), symptomatic peripheral artery disease (50.0\%; 95\% CI 0.0-100\%), current smokers (19.0\%; 95\% CI $0.7-37.4 \%)$, and in persons taking lipid lowering medication (13.1\%; 95\% CI 4.4-21.8\%), platelet or anticoagulant medication (15.1\%; 95\% CI 5.1-25.1\%), or a history of any cardiovascular event (15.9\%; 95\% CI 4.7 $27.2 \%)$. We determined, with the binomial test, that the

Table 1 Demographic data of all persons undergoing panoramic radiograph examination

\begin{tabular}{clccc}
\hline Group & & $\mathbf{n}$ & $\begin{array}{c}\text { Included } \\
\mathbf{n}(\%)\end{array}$ & Significance* $^{*}$ \\
\hline Sex & Women & 557 & $53(9.5 \%)$ & $\mathrm{p}=0.677$ \\
& Men & 625 & $64(10.2 \%)$ & \\
Age (years) & $<65$ & 827 & $40(4.8 \%)$ & $\mathrm{p}<0.0001$ \\
& $65-74$ & 355 & $77(21.7 \%)$ & \\
Indication for & Regular dental & 668 & $94(14.1 \%)$ & $\mathrm{p}<0.0001 \neq$ \\
panoramic & Specialised dental & 279 & $6(2.2 \%)$ & \\
examinationt & Specialised medical & 235 & $17(7.2 \%)$ & \\
All & & 1182 & $117(10.1 \%)$ & - \\
\hline
\end{tabular}

${ }^{*}$ Chi-2-test.

† Regular dental - examinations performed in all practices using panorama, e.g. dental and implant treatment. Specialised dental - examinations performed in specialist dental clinics such as fractures and orthodontics. Specialised medical - examinations routinely performed prior to medical interventions, e.g. heart valve surgery.

‡ Overall difference between the three groups. prevalence of $50-99 \%$ carotid stenosis was significant over the $5 \%$ pre-specified threshold in the following subgroups: men $(\mathrm{p}=0.014)$, history of myocardial infarction ( $p=0.030)$, current angina $(p=0.009)$, symptomatic peripheral artery disease $(p=0.014)$, current smoking ( $\mathrm{p}=0.019)$, taking lipid lowering medication ( $\mathrm{p}=0.011)$, taking platelet inhibiting or anticoagulant medication ( $\mathrm{p}=0.005)$, and history of any cardiovascular event $(\mathrm{p}=0.006)$.

The mean age for included persons with calcification in the area of the carotid arteries was higher compared to all other persons examined with panorama without calcifications in the area of the carotid arteries, 66.9 years (SD $5.6)$ versus 49.8 years (SD 18.1), $\mathrm{p}<0.001$. The persons with calcification in the area of the carotid arteries had a higher prevalence of all cardiovascular parameters and most differences were statistically significant (Table 3).

Calcification in the area of the carotid arteries appeared unilaterally in 40 included persons and bilaterally in 77 persons. All nine carotid stenoses had a calcification in the area of the carotid arteries on the corresponding neck side. Five persons had 50-69\% stenosis and were managed with medical cardiovascular prevention and reexamination of their carotid stenosis. Three persons had a 70-99\% carotid stenosis (one of these also had a contralateral 50-69\% stenosis). These persons were offered CEA: one underwent CEA, one refused, and one died before the operation. We detected no carotid occlusions. We detected a calcified atherosclerotic lesion (causing a $<50 \%$ stenosis) in 99\% (108/109) of the persons with calcifications in the area of the carotid arteries but without a $50-99 \%$ carotid stenosis. The time between the panoramic examination and the ultrasound examination was 83 days (SD 54) on average. 
Table 2 Factors influencing the prevalence of $50-99 \%$ carotid stenosis among included persons

\begin{tabular}{|c|c|c|c|c|c|}
\hline & & Yes & & No & Significance* $^{*}$ \\
\hline & $\mathrm{n}$ & $\begin{array}{c}\text { With stenosis } \\
n(\%) \\
{[95 \% \mathrm{Cl}]}\end{array}$ & $\mathbf{n}$ & $\begin{array}{c}\text { With stenosis } \\
\mathrm{n}(\%) \\
{[95 \% \mathrm{Cl}]}\end{array}$ & \\
\hline Women & 53 & $\begin{array}{c}0(0 \%) \\
{[N A]}\end{array}$ & 64 & $\begin{array}{c}8(12.5 \%) \\
{[4.2-20.8 \%]}\end{array}$ & $p=0.008$ \\
\hline $65-74$ years of aget & 77 & $\begin{array}{c}6(7.8 \%) \\
{[1.7-13.9 \%]}\end{array}$ & 40 & $\begin{array}{c}2(5.0 \%) \\
{[0.0-12.1 \%]}\end{array}$ & $p=0.570$ \\
\hline Regular dental & 94 & $\begin{array}{c}5(5.3 \%) \\
{[0.7-9.9 \%]}\end{array}$ & 23 & $\begin{array}{c}3(13.0 \%) \\
{[0.0-27.9 \%]}\end{array}$ & $p=0.188$ \\
\hline Myocardial infarction & 24 & $\begin{array}{c}4(16.7 \%) \\
{[0.6-32.7 \%]}\end{array}$ & 93 & $\begin{array}{c}4(4.3 \%) \\
{[0.1-8.5 \%]}\end{array}$ & $p=0.032$ \\
\hline Heart Failure & 6 & $\begin{array}{c}0(0 \%) \\
{[N A]}\end{array}$ & 111 & $\begin{array}{c}8(7.2 \%) \\
{[2.3-12.1 \%]}\end{array}$ & $p=0.496$ \\
\hline Current angina & 17 & $\begin{array}{c}4(23.5 \%) \\
{[1.1-46.0 \%]}\end{array}$ & 100 & $\begin{array}{c}4(4.0 \%) \\
{[0.1-7.9 \%]}\end{array}$ & $p=0.003$ \\
\hline Symptomatic peripheral artery disease & 4 & $\begin{array}{c}2(50.0 \%) \\
{[0.0-100 \%]}\end{array}$ & 113 & $\begin{array}{c}6(5.3 \%) \\
{[1.1-9.5 \%]}\end{array}$ & $p=0.0005$ \\
\hline Diabetes & 32 & $\begin{array}{c}3(9.4 \%) \\
{[0.0-20.1 \%]}\end{array}$ & 85 & $\begin{array}{c}5(5.9 \%) \\
{[0.8-11.0 \%]}\end{array}$ & $p=0.505$ \\
\hline Hypertension & 88 & $\begin{array}{c}8(9.1 \%) \\
{[3.0-15.2 \%]}\end{array}$ & 29 & $\begin{array}{c}0(0 \%) \\
{[\mathrm{NA}]}\end{array}$ & $p=0.093$ \\
\hline Current smoking & 21 & $\begin{array}{c}4(19.0 \%) \\
{[0.7-37.4 \%]}\end{array}$ & 96 & $\begin{array}{c}4(4.2 \%) \\
{[0.1-8.2 \%]}\end{array}$ & $p=0.014$ \\
\hline Blood pressure medicine & 85 & $\begin{array}{c}8(9.4 \%) \\
{[3.1-15.7 \%]}\end{array}$ & 32 & $\begin{array}{c}0(0 \%) \\
{[N A]}\end{array}$ & $p=0.072$ \\
\hline Lipid lowering medicine & 61 & $\begin{array}{c}8(13.1 \%) \\
{[4.4-21.8 \%]}\end{array}$ & 56 & $\begin{array}{c}0(0 \%) \\
{[\mathrm{NA}]}\end{array}$ & $p=0.005$ \\
\hline Platelet inhibiting or anticoagulant medicine & 53 & $\begin{array}{c}8(15.1 \%) \\
{[5.1-25.1 \%]}\end{array}$ & 64 & $\begin{array}{c}0(0 \%) \\
{[N A]}\end{array}$ & $p=0.0013$ \\
\hline Any cardiovascular event & 44 & $\begin{array}{c}7(15.9 \%) \\
{[4.7-27.2 \%]}\end{array}$ & 73 & $\begin{array}{c}1(1.4 \%) \\
{[0.0-4.1 \%]}\end{array}$ & $p=0.003$ \\
\hline Any cardiovascular risk factor & 101 & $\begin{array}{c}8(7.9 \%) \\
{[2.6-13.3 \%]}\end{array}$ & 16 & $\begin{array}{c}0(0 \%) \\
{[\mathrm{NA}]}\end{array}$ & $p=0.243$ \\
\hline All & 117 & $\begin{array}{c}8(6.8 \%) \\
{[2.2-11.5 \%]}\end{array}$ & - & - & - \\
\hline
\end{tabular}

Differences between basic and cardiovascular subgroups in participants with calcification in the area of the carotid arteries. Based on persons, not individual neck-sides.

${ }^{*}$ Chi-2-test

† We detected no difference in mean age between the persons with (68.4 years SD 4.5) and without (66.8 years SD 5.6) carotid stenosis, $\mathrm{p}=0.44$ (t-test)

₹Regular dental - examinations performed in all practices using panorama, e.g. dental and implant treatment.

\section{Discussion}

The main finding of this study was the high prevalence of significant $(50-99 \%)$ carotid stenosis in men with incidentally detected calcification in the area of the carotid artery seen on panoramic examinations. Thus, in this subpopulation, directed screening for asymptomatic carotid stenosis is indicated [12].

We missed six out of 123 eligible persons in the study. Thus the inclusion rate of the intended population was good. The kappa values for the existence of a calcification in the area of the carotid arteries on each side of the neck showed good agreement between observers.

We detected a different rate of calcifications in the area of the carotid arteries compared with previous studies $[13,14]$. This difference has at least three possible explanations: 1) Not all panoramic examinations include the area of the carotid arteries, thus calcifications in the vessels can be missed. 2) For inclusion in the study, we required that the calcification in the area of the carotid arteries seen on panoramic radiograph should be confirmed on APP. A calcification can be undetectable in the APP examination if the spine superimposes the calcification. This may have reduced the number of detected calcifications in the area of the carotid arteries in this study. 3) There are several known risk factors for arterial calcification such as age, dietary factors, and smoking habits that differ among geographic areas [17]. Thus, it is possible that the prevalence of calcifications in the area of the carotid arteries varies between different studies populations. 
Table 3 Comparisons between included persons and reference persons

\begin{tabular}{lccc}
\hline & $\begin{array}{c}\text { Included persons } \\
\mathbf{n}(\%)\end{array}$ & $\begin{array}{c}\text { Reference persons } \\
\mathbf{n ~ ( \% )}\end{array}$ & Significance* \\
\hline Women & $53(45.3 \%)$ & $56(47.1 \%)$ & $p=0.786$ \\
$65-74$ years & $77(65.8 \%)$ & $79(66.4 \%)$ & $p=0.926$ \\
Indication - Regular dentalt & $94(80.3 \%)$ & $100(84.0 \%)$ & $p=0.458$ \\
Myocardial infarction & $24(20.5 \%)$ & $7(5.9 \%)$ & $p=0.0009$ \\
Heart Failure & $6(5.1 \%)$ & $3(2.5 \%)$ & $p=0.296$ \\
Current angina & $17(14.5 \%)$ & $2(1.7 \%)$ & $p=0.0003$ \\
Symptomatic peripheral artery disease & $4(3.4 \%)$ & $1(0.8 \%)$ & $p=0.169$ \\
Diabetes & $32(27.4 \%)$ & $10(8.4 \%)$ & $p=0.00014$ \\
Hypertension & $88(75.2 \%)$ & $54(45.4 \%)$ & $p<0.0001$ \\
Current smoking & $21(17.9 \%)$ & $8(6.7 \%)$ & $p=0.009$ \\
Blood pressure medicine & $85(72.6 \%)$ & $56(47.1 \%)$ & $p<0.0001$ \\
Lipid lowering medicine & $61(52.1 \%)$ & $27(22.7 \%)$ & $p<0.0001$ \\
Platelet inhibiting or anticoagulant medicine & $53(45.3 \%)$ & $34(28.6 \%)$ & $p=0.008$ \\
Any cardiovascular event & $44(37.6 \%)$ & $12(10.1 \%)$ & $p<0.0001$ \\
Any cardiovascular risk factor & $101(86.3 \%)$ & $78(65.5 \%)$ & $p=0.00019$ \\
All & 117 & 119 & - \\
\hline
\end{tabular}

Differences in the rate of basic and cardiovascular subgroup findings between included persons with a calcification in the area of the carotid arteries and reference persons.

${ }^{*}$ Chi-2-test

† Regular dental - examinations performed in all practices using panorama, e.g. dental and implant treatment.

We detected differences in the proportion of included persons between the three referral subgroups. The 'regular dental' subgroup had the highest rate of inclusion in the study; persons in the 'specialised dental' subgroup were younger (mean age 36.5 years, SD 17.3) and should therefore have a lower degree of atherosclerosis. Thirty of 47 persons with calcification in the area of the carotid arteries in the 'specialised medical' group were excluded; in most cases, these persons were referred for the panoramic radiographs due to a diagnosis of cancer or serious co-morbidity and were excluded since these diagnoses made them ineligible for asymptomatic CEA.

We included a sex- and age-matched reference group in order to determine if the persons with calcification in the area of the carotid arteries have an average or above average burden of atherosclerotic disease. The reference group was representative for age, sex, and cause of referral for the panoramic examination compared to study persons with calcifications in the area of the carotid arteries. Based on the differences seen in Table 3 we believe that persons with calcification in the area of the carotid arteries have an above average burden of atherosclerotic disease. In general, arterial calcification is more prevalent in persons with cardiovascular disease [17]; thus, this finding was expected.

It is uncertain what the lowest degree of carotid stenosis is that entails benefit with asymptomatic CEA. The results from the ACST study suggest that asymptomatic CEA is of similar benefit for persons with 70-99\% and with 50$69 \%$ carotid stenosis [2]. Ongoing studies might clarify the benefit vs. risk ratio of carotid surgery or stenting in various degrees of asymptomatic carotid stenoses [7]. Due to the present uncertainty in clinical indication, we have presented data for $50-99 \%$ carotid stenosis.

Overall, we detected a lower prevalence of carotid stenosis in persons with calcification in the area of the carotid arteries compared with previous studies $[13,14]$. One reason for this is that we only examined persons eligible for asymptomatic CEA, with age below 75 years $[1,2]$. Persons $>75$ years of age were examined in previously published studies $[13,14]$ and the prevalence of carotid stenosis increases with increasing age [11]. In the largest of the previous studies, 94\% of included persons were men [13]; we found men to have a higher prevalence of carotid stenosis.

We found several significant subgroup heterogeneities for the prevalence of $50-99 \%$ carotid stenosis. These finding were expected since they mark atherosclerotic disease in other parts of the body. These clinical features are most certainly not independent of each other, for example: persons with vascular events are prescribed the medications analysed. A multivariate analysis to test for independence was not performed since the total number of outcomes - i.e. 50-99\% carotid stenosis - was few ( $\mathrm{n}=$ 8). We advocate that until such a multivariate analysis can be performed in a larger study, only male sex should be used as basis for selection to carotid screening with ultrasound since: (1) it is one of few factors available to dentists; (2) it was one of few factors that was clinically useful, i.e. in addition to be significant, when positive, it included all findings of carotid stenosis. 
Age did not affect the prevalence of carotid stenosis in the included population. This could be a false negative finding since the prevalence of carotid stenosis increases with increasing age [11]. However, until shown otherwise, age should not be used as a criterion to go ahead with or abstain from carotid ultrasound screening in persons $<75$ years with calcifications in the area of the carotid arteries.

We have not analysed the appearance (intensity, size, and/or shape) of the calcification in the area of the carotid arteries on the panoramic images. These factors might be useful to further select persons for carotid screening.

Our further clinical experience confirms the results presented here: between the study's stop date in February 2009 and February 2011, we have found 65 additional men with calcification in the area of the carotid arteries on panoramic examinations. Carotid ultrasound examinations revealed that six of these individuals had $50-99 \%$ carotid stenosis and two have undergone CEA. The carotid ultrasound examinations also revealed an aneurysm (12 $\mathrm{mm}$ in diameter) of the internal carotid artery in one person and a carotid occlusion in one person. Our collected experience is that, of 129 men with calcification in the area of the carotid arteries found on panoramic radiographs, 14 (10.9\%, 95\%CI 5.4-16.3\%) had a $50-99 \%$ carotid stenosis and $15(11.6 \%, 95 \% \mathrm{CI}$ 6.0-17.2\%) had a 50-100\% carotid stenosis; significantly over the $5 \%$ pre-specified threshold, $\mathrm{p}=0.005$ and $\mathrm{p}=$ 0.002 respectively (Binomial test).

The findings of this study must be interpreted with caution since we did not find a prevalence of carotid stenosis $>5 \%$ in the whole study group, but only in subgroups [18]. However, previous similar studies on panoramic examination report the prevalence of 50-99\% carotid stenosis to be $>5 \%[13,14]$ of persons with calcifications in the area of the carotid arteries; the reproducibility of this finding strengthens this study's finding [18]. Carotid ultrasound was not performed on persons in the reference group. There were too few cases to perform a multivariate subgroup analysis. We did not analyse on the appearance of the calcification in the area of the carotid arteries. This warrants further studies, which we plan to conduct.

The high prevalence of carotid stenosis in the persons with calcifications in the area of the carotid arteries was probably influenced by both the revelation of a local atherosclerotic process and by the above average burden of generalised atherosclerotic disease. To what extent each factor contributed to this finding is unknown.

We only included persons that were eligible for asymptomatic CEA; this mirrors clinical practice. Contrary to the largest previous study, men and women were included in almost equal proportions; however, only men were found to have carotid stenosis. Thus, this study is externally valid for both sexes. There were no significant differences in the prevalence of $50-99 \%$ carotid stenosis between the subgroups based on reason for referral for the panoramic examination. The results are valid for dentists in general practice and for centres that perform examinations corresponding to the subgroups 'regular dental' or 'specialised dental'.

The design of this study intended to mirror a clinical practice based from the ACST study [2]; the conclusion was based on a threshold for what prevalence of carotid stenosis is required for carotid screening that was calculated for the same clinical practice [12]. Nowadays, statin treatment is more common than at the time of the ACST study; Recent, ongoing, and coming trials will determine if asymptomatic CEA is still indicated in patients with statin and other cardiovascular preventive treatment, and in whom asymptomatic CEA is of benefit [7-10]. Thus, it is likely that the clinical practice for persons with asymptomatic carotid stenosis will change within a few years. If so, the threshold for what prevalence of carotid stenosis is required for carotid ultrasound screening must be recalculated based on that clinical practice. Our results should then be compared to this new threshold and the conclusions revised if necessary.

\section{Conclusions}

Carotid screening with ultrasound should be performed in men with the incidental finding of calcification in the area of the carotid arteries seen on panoramic examinations, confirmed with an anterio-posterior examination, if they are otherwise eligible for asymptomatic carotid endarterectomy.

\section{List of abbreviations}

APP: Anterio-Posterior Projection; CEA: Carotid EndArterectomy; SD: Standard Deviation; TIA: Transient Ischemic Attack.

\section{Acknowledgements and funding}

The authors acknowledge the assistance of the staff in the department of Oral and Maxillofacial Radiology for their continuous work to make the data available during the study, the help of Fredrik Hermansson in gathering data on the reference population, and the advice from Marie Eriksson, statistician. This study was supported by the Swedish Heart and Lung Foundation, the Swedish Stroke Foundation, the Northern Swedish Stroke Fund, the County of Västerbotten, and the medical faculty of Umeå University.

\section{Author details}

'Department of Public Health and Clinical Medicine, Umeå University, Umeå, Sweden. ${ }^{2}$ Department of Odontology, Umeå University, Umeå, Sweden. ${ }^{3}$ Clinical physiology, Department of Surgical and Perioperative Sciences, Umeå University, Umeå, Sweden.

\section{Authors' contributions}

EPJ assisted in the study design, gathered most of the data, analyzed all the data, and wrote the first draft of the manuscript. JA came up with the general study design, gathered some of the data, made constructive comments to the manuscript, and served as mentor for MG. MG gathered some of the data and wrote minor parts of the manuscript. KK was 
responsible for the carotid ultrasound examinations and made constructive comments to the manuscript. ELJ assisted in the study design, gathered some of the data, made constructive comments to the manuscript, and served as mentor for MG. PW came up with the general study design, made constructive comments to the manuscript, and served as mentor for EPJ. All authors have read and approved the final version of the manuscript.

\section{Competing interests}

The authors declare that they have no competing interests.

Received: 10 March 2011 Accepted: 13 July 2011

Published: 13 July 2011

\section{References}

1. Chambers BR, Donnan GA: Carotid endarterectomy for asymptomatic carotid stenosis. Cochrane Database of Systematic Reviews 2005, 4: CD001923.

2. Halliday A, Harrison $M$, Hayter $E$, Kong $X$, Mansfield A, Marro J, Pan H, Peto R, Potter J, Rahimi K, Rau A, Robertson S, Streifler J, Thomas D, on behalf of the Asymptomatic Carotid Surgery Trial (ACST) Collaborative Group: 10-year stroke prevention after successful carotid endarterectomy for asymptomatic stenosis (ACST-1): a multicentre randomised trial. Lancet 2010, 376:1074-1084.

3. Abbott AL: Medical (Nonsurgical) Intervention Alone Is Now Best for Prevention of Stroke Associated With Asymptomatic Severe Carotid Stenosis Stroke. Stroke 2009, 40:e573-e583.

4. The ESO Guidelines. [http://www.eso-stroke.org/recommendations.php].

5. Brott TG, Halperin JL, Abbara S, Bacharach JM, Barr JD, Bush RL, Cates CU, Creager MA, Fowler SB, Friday G, Hertzberg VS, Mclff EB, Moore WS, Panagos PD, Riles TS, Rosenwasser RH, Taylor AJ: 2011 ASA/ACCF/AHA/ AANN/AANS/ACR/ASNR/CNS/SAIP/SCAI/SIR/SNIS/SVM/SVS Guideline on the Management of Patients With Extracranial Carotid and Vertebral Artery Disease. JACC 2011, 57:e16-94.

6. The Swedish National Board of Health and Welfare ("Socialstyrelsen") Stroke Guidelines from 2005. [http://www.socialstyrelsen.se/Lists/ Artikelkatalog/Attachments/8934/2007-102-10_200710210.pdf].

7. Reiff $T$, Stingele $R$, Eckstein $H H$, Fraedrich $G$, Jansen $O$, Mudra $H$, Mansmann U, Hacke W, Ringleb P, SPACE 2-Study Group: Stent-protected angioplasty in asymptomatic carotid artery stenosis vs. endarterectomy: SPACE2 - a three-arm randomised-controlled clinical trial. Int J Stroke 2009, 4:294-299.

8. Nicolaides AN, Kyriacou E, Griffin M, Sabetai M, Thomas DJ, Tegos T, Geroulakos G, Labropoulos N, Doré CJ, Morris TP, Naylor R, Abbott AL, for the Asymptomatic Carotid Stenosis and Risk of Stroke (ACSRS) Study Group: Asymptomatic internal carotid artery stenosis and cerebrovascular risk stratification. J Vasc Surg 2010, 52:1486-1496.

9. Markus HS, King A, Shipley M, Topakian R, Cullinane M, Reihill S, Bornstein NM, Schaafsma A: Asymptomatic embolisation for prediction of stroke in the Asymptomatic Carotid Emboli Study (ACES): a prospective observational study. Lancet Neurol 2010, 9:663-671.

10. King a, Serena J, Bornstein NM, Markus HS, ACES Investigators: Does Impaired Cerebrovascular Reactivity Predict Stroke Risk in Asymptomatic Carotid Stenosis? A Prospective Substudy of the Asymptomatic Carotid Emboli Study. Stroke 2011, 42:1550-1555.

11. de Weerd M, Greving JP, Hedblad B, Lorenz MW, Mathiesen EB, O'Leary DH, Rosvall M, Sitzer M, Buskens E, Bots ML: Prevalence of Asymptomatic Carotid Artery Stenosis in the General Population An Individual Participant Data Meta-Analysis. Stroke 2010, 41:1294-1297.

12. Qureshi Al, Alexandrov AV, Tegeler CH, Hobson RW II, Baker JD, Hopkins LN: Guidelines for Screening of Extracranial Carotid Artery Disease: A Statement for Healthcare Professionals from the Multidisciplinary Practice Guidelines Committee of the American Society of Neuroimaging; Cosponsored by the Society of Vascular and Interventional Neurology. J Neuroimaging 2007, 17:19-47.

13. Friedlander AH, Garrett NR, Chin EE, Baker JD: Ultrasonographic confirmation of carotid artery atheromas diagnosed via panoramic radiography. J Am Dent Assoc 2005, 136:635-640.

14. Almog DM, Horev T, Illig KA, Green RM, Carter LC: Correlating carotid artery stenosis detected by panoramic radiography with clinically relevant carotid artery stenosis determined by duplex ultrasound. Oral Surg Oral Med Oral Pathol Oral Radiol Endod 2002, 94:768-773.
15. Hansen F, Bergqvist D, Lindblad B, Lindh M, Mätzsch T, Länne T: Accuracy of Duplex Sonography berfore Carotid Endarterectomy - A Comparison with Angiography. Eur J Vasc Endovasc Surg 1996, 12:331-336.

16. Ågren Wilsson A, Backman C, Fagerlund M, Malm J: Quality assurance of ultrasound prior to carotid surgery must be effected locally. Läkartidningen 2000, 97:2313-2316.

17. Nicoll $R$, Henein M: Extensive coronary calcification: a clinically unrecognised condition. Curr Vasc Pharmacol 2010, 8:701-705.

18. Rothwell PM: Subgroup analysis in randomized controlled trials: importance, indications and interpretation. Lancet 2005, 365:176-186.

\section{Pre-publication history}

The pre-publication history for this paper can be accessed here: http://www.biomedcentral.com/1471-2261/11/44/prepub

\section{doi:10.1186/1471-2261-11-44}

Cite this article as: Johansson et al.: Ultrasound screening for asymptomatic carotid stenosis in subjects with calcifications in the area of the carotid arteries on panoramic radiographs: a cross-sectional study. BMC Cardiovascular Disorders 2011 11:44.

\section{Submit your next manuscript to BioMed Central and take full advantage of:}

- Convenient online submission

- Thorough peer review

- No space constraints or color figure charges

- Immediate publication on acceptance

- Inclusion in PubMed, CAS, Scopus and Google Scholar

- Research which is freely available for redistribution

Submit your manuscript at www.biomedcentral.com/submit
C) Biomed Central 